Herbia Araujo Soares ${ }^{1}$

Luciana Silva Aguiar Mendes Barros²

\title{
Tecnologias da informação e \\ comunicação na formação inicial do professor de arte: um estudo sobre currículo de artes visuais da UFMA
}

Information and communication technologies in the initial education of the art teacher: a study on UFMA's visual arts curriculum

Las tecnologías de la información y la comunicación en la formación inicial del profesor de arte: un estudio sobre el currículo de artes visuales de la UFMA 


\section{Resumo}

As tecnologias educacionais estão inseridas na matriz curricular de muitas Instituições de Ensino Superior, no intuito de preparar os discentes com um conhecimento básico sobre o tema. Este trabalho tem como objetivo principal observar a inserção das tecnologias no currículo do curso de licenciatura em Artes Visuais da Universidade Federal do Maranhão - UFMA, analisando, de forma comparativa, os Projetos Pedagógicos de 2010 e 2017. Os resultados obtidos, indicam-nos que as tecnologias são abordadas em algumas disciplinas como Arte e as novas tecnologias, dentre outras que visam atender a reestruturação do curso de Artes Visuais, e suprir a demanda de um público que é interativo e conectado. Para este estudo, optou-se pela pesquisa documental, estudo de caso e bibliográfica, fundamentando a discussão a partir das concepções de autores como Pimentel (2011), Cernev e Guerra (2017), Frizon (2015), Moran (2013), dentre outros. Assim, espera-se que as inquietações sobre a formação inicial dos professores de Arte levantados ao longo do trabalho contribuam para a reflexão da necessidade de aliar teoria e prática docente por meio da criação e ampliação de novos fazeres pedagógicas que potencializam o uso das tecnologias digitais em sala de aula.

Palavras-chave: Tecnologia; Formação de Professores; Licenciatura em Arte

\section{Abstract}

Educational technologies are included in the curriculum of many Higher Education Institutions, in order to prepare students with a basic knowledge of the subject. This work has as main objective to observe the insertion of technologies in the curriculum of the degree course in Visual Arts at the Federal University of Maranhão UFMA, analyzing, in a comparative way, the Pedagogical Projects of 2010 and 2017. The results obtained indicate that the technologies are addressed in some disciplines such as Art and new technologies, among others that aim to meet the restructuring of the Visual Arts course, and meet the demand of an audience that is interactive and connected. For this study, we opted for documentary research, case study and bibliography, basing the discussion on the conceptions of authors such as Pimentel (2011), Cernev and Guerra (2017), Frizon (2015), Moran (2013), among others. Thus, it is expected that the concerns about the initial training of Art teachers raised throughout the work contribute to the reflection on the need to combine theory and teaching practice through the creation and expansion of new pedagogical practices that enhance the use of digital technologies in the classroom.

1 Mestranda em Gestão de Ensino da Educação Básica (PPGEEB), pela Universidade Federal do Maranhão. E-mail:soaresherbia@gmail.com. CV: http://lattes.cnpq.br/6636985972797657. Orcid:0000-0003-4272-1212.

2 Doutora em Informática na Educação e professora do Instituto Federal de Educação, Ciência e Tecnologia do Maranhão. E-mail: lucianabarros@ifma.edu.br. http://lattes.cnpq.br/9454519770693683. https://orcid.org/00000003-2898-952X. 
Keywords: Technology; Teacher's Formation; Degree in

\section{Resumen}

Las tecnologías educativas están incluidas en el plan de estudios de muchas instituciones de educación superior, con el fin de preparar a los estudiantes con un conocimiento básico de la materia. Este trabajo tiene como objetivo principal observar la inserción de tecnologías en el plan de estudios de la carrera de Artes Visuales de la Universidad Federal de Maranhão - UFMA, analizando, de manera comparativa, los Proyectos Pedagógicos de 2010 y 2017. Los resultados obtenidos indican que las tecnologías se abordan en algunas disciplinas como el Arte y las nuevas tecnologías, entre otras que tienen como objetivo atender la reestructuración del curso de Artes Visuales, y satisfacer la demanda de una audiencia interactiva y conectada. Para este estudio se optó por la investigación documental, el estudio de caso y la bibliografía, basando la discusión en las concepciones de autores como Pimentel (2011), Cernev y Guerra (2017), Frizon (2015), Moran (2013), entre otros. Assim, espera-se que as inquietações sobre a formação inicial dos professores de Arte levantados ao longo do trabalho contribuam para a reflexão da necessidade de aliar teoria e prática docente por meio da criação e ampliação de novos fazeres pedagógicas que potencializam o uso das tecnologias digitais En el aula.

Palabras clave: Tecnología; Formación de profesores; Grado en Arte 


\section{Introdução}

O século XXI trouxe transformações consideráveis para a sociedade, com inúmeras mudanças em todas as dimensões da vida humana. O avanço tecnológico é perceptível, tendo em vista a reconfiguração na forma de organização social e profissional, na forma de comunicação e nas relações entre os indivíduos. Nota-se que boa parte dessas modificações foram deflagradas pelo advento das tecnologias digitais.

Considerando que as tecnologias digitais têm provocado mudanças na sociedade de modo geral, Frizon (2015, p.193) aponta essa necessidade por considerar que o espaço acadêmico precisa ser redimensionado para atender as demandas atuais. Os cursos superiores de licenciatura precisam preparar os futuros docentes para o uso eficaz das tecnologias digitais e para atender a esse redimensionamento. Além disso, os espaços educacionais precisam se adequar respeitando as leis e diretrizes que regem a educação no país.

Tais mudanças foram reverberadas no curso de Educação Artística ${ }^{3}$ da Universidade Federal do Maranhão - UFMA 4 que, atendendo aos processos de reformulação curricular, adequou suas estruturas às mudanças do ensino superior em Arte e, de acordo com as diretrizes para o Ensino Superior, elaboradas pelo MEC.

A escolha pelo tema e pelo objeto de pesquisa são decorrentes das questões levantadas ao longo da formação acadêmica na graduação em Educação Artística na UFMA, na qual surgiram as primeiras inquietações acerca da utilização das tecnologias. Nesse sentido, questiona-se: como o projeto pedagógico do curso de licenciatura em Artes Visuais da UFMA dialoga com as tecnologias digitais? Quais as disciplinas contidas no $\mathrm{PPC}^{5}$ que fazem referência à tecnologia no ensino de Artes Visuais? Quais as mudanças percebidas entre o PPC de 2010 e 2017 que fortalecem a formação inicial?

Com base nesse contexto, o presente estudo tem como objetivo geral analisar de forma comparativa os PPC's de 2010 e 2017, a fim de observar possíveis mudanças relacionadas à inserção das tecnologias no currículo do curso de licenciatura em Artes Visuais da UFMA.

No intuito de responder aos questionamentos levantados, esse trabalho está organizado em três partes. A primeira contempla as discussões acerca da "Tecnologia no ensino superior: o processo de formação inicial de professores" que faz uma reflexão sobre as novas expectativas de formação na educação superior. A segunda, intitulada "A formação dos professores de Artes Visuais: novas possibilidades com as tecnologias

3 Graduação em Educação Artística: Criado em 1978, através do Parecer no 781/78 do Conselho Federal de Educação (CFE), começam a surgir no país os primeiros cursos de Licenciatura Plena em Educação Artística, com duração de 04 (quatro) anos, a partir de um currículo estabelecido por lei, com uma "proposta de polivalênciaArtes plasticas, Música, Dança e Teatro" (BIASOLI, 1999, p. 75).

4 UFMA: Ao Ingo do texto se usará a sigla UFMA para se referir a Universidade Federal do Maranhão

5 PPC: Utiliza-se a sigla PPC para se referir ao projeto pedagógico- Documento que normatiza a estrutura curricular do curso de Licenciatura em Artes Visuais. 
digitais" que fomenta discussões sobre os novos fazeres em Arte ditados pelas tecnologias digitais ao trabalho docente. Já a terceira e última parte versará sobre a análise comparativa entre os PPC 's 2010 e 2017 do curso de Artes Visuais da UFMA.

Quanto aos procedimentos metodológicos, este estudo caracterizou-se como uma pesquisa documental, estudo de caso e bibliográfica. Em relação à pesquisa documental, foram utilizados como fonte de informações os documentos supracitados. No que tange ao Estudo de Caso, foi uma pesquisa aprofundada sobre os programas pedagógicos da UFMA, necessário para entender tais problemáticas, visando compreender a configuração, de forma ampla e detalhada. Para embasamento teórico deste estudo, recorreu-se à pesquisa bibliográfica especializada, que fundamenta os conceitos necessários para compreensão do tema, além de abordar a forma como as tecnologias digitais contribuem para a formação inicial do professor de Arte. Para tal, buscou-se aporte teórico em autores como Pimentel (2011), Cernev e Guerra (2017), Frizon (2015), Moran (2013), dentre outros.

Considera-se a pesquisa importante e necessária para compreender como os discentes estão sendo formados diante dos novos desafios oriundos da revolução tecnológica presentes na Universidade, bem como para analisar as dificuldades encontradas na relação tecnologia/ensino.

\section{Tecnologia no ensino superior: o processo de formação inicial de professores}

As Tecnologias da Informação e Comunicação (TDICS ${ }^{6}$ ) apresentam-se em frequentes transformações, nas quais observa-se um considerável número de possibilidades para novas interações e comunicação entre professor-aluno.

Nessa perspectiva, novas expectativas de formação pressupõem ruptura com padrões e modelos rígidos e, em muitos casos, indiferenciados de educação superior, implicando em mudanças no perfil de formação, qualificando-a no tocante ao domínio de conhecimento e na capacidade de aplicá-lo criativamente, bem como na maior adaptabilidade à mudança tecnológica, de informação e comunicação.

A relação entre tecnologia e formação de professores, surge um novo campo de conhecimento, a Tecnodocência, desenvolvido por Luciana de Lima e Robson Carlos Loureiro desde 2013 e formalizada em 2015 com a publicação do livro intitulado com o mesmo termo. A proposta foi construída com o objetivo de possibilitar aos professores da Educação Básica e Ensino Superior, em seus processos formativos, uma ampliação do arcabouço teórico sobre o uso e o desenvolvimento de TDICS na docência. Desta forma, Lima e Loureiro, apresentam essa área de pensamento como:

6 TDICS: Ao longo do texto se usará a sigla TDICS para fazer menção a utilização de Tecnologias Digitais da Informação e Comunicação. 
"A integração entre docência e TICs com base epistemológica interdisciplinar e transdisciplinar por meio da utilização dos conhecimentos prévios do aprendiz (professores e alunos) para o desenvolvimento de uma reflexão crítica sobre os processos tramados de ensino, aprendizagem e avaliação". (LIMA; LOUREIRO, 2019, p.46).

Considerando a necessidade de reflexão sobre os processos educativos, é notório saber que o aprendizado é condição sine qua non para utilização dos recursos tecnológicos e, consequentemente, para o bom exercício da docência. Para Moran, "o trabalho educativo mediado por tecnologias digitais oferece aos participantes a chance de se engajar, aprender e desenvolver relações duradouras para suas vidas". Ensinar e aprender podem ser feitos de forma muito mais flexível, ativa e focada no ritmo de cada um (MORAN, 2013 p.2).

Pressupõe-se com isto que essa mudança deveria iniciar pelos cursos de licenciatura, uma vez que estes deveriam habilitar os futuros docentes para o uso consciente das tecnologias digitais, colaborando com o discente na construção das capacidades cognitivas que são necessárias para que se efetive os processos de ensino e de aprendizagem.

Nessa perspectiva, Frizon (et al, 2015, p. 1093) discorre que:

Os cursos superiores de licenciatura precisam preparar os futuros docentes para o uso eficaz das tecnologias digitais, contribuindo com o aluno no desenvolvimento das capacidades cognitivas que são requeridas para que se concretize os processos de ensino e de aprendizagem (FRIZON et al, 2015, p. 1093).

Assim, o questionamento é: como preparar esse acadêmico, futuro professor, para intermediar o processo de ensino - tecnologia, diante das dificuldades e desafios existentes na escola atual?. As barreiras educacionais observadas no Brasil são complexas, e abrangentes, possiveis de ser vistas através de aspectos estruturais, pedagógicos, financeiros, sociais, culturais, que afetam diretamente o desenvolvimento da educação no país, não conseguindo acompanhar o ritmo com que as novas informações chegam aos discentes do curso superior, pois são rápidas e constantes, vão de um ponto a outro em questão de minutos, situação até pouco tempo impensada.

Diante dessas contínuas transformações, faz-se necessário vislumbrar uma formação acadêmica que ultrapasse os limites do ensino tradicional, considerando a busca de uma educação emancipatória, que implique em uma formação qualificadora para uma nova prática pedagógica capaz de proporcionar conhecimento de estratégias, habilidades e metodologias para a utilização das TDICS, de forma a integrá-las no currículo de diferentes formas.

Foi o que aconteceu na década de 1980 na area de formação em Arte, "incomodados com a fraca formação em artes dos cursos de Educação Artística, que tinham currículo unificado para todo o Brasil, se organizaram em associações es- 
taduais que, em 1988, criaram a Federação de Arte-Educadores do Brasil - FAEB" (PIMENTEL 2017, p. 2840). Sobre essa formação entendia-se que:

\begin{abstract}
Com a união de esforços, o panorama da formação de professores e do ensino/aprendizagem em Arte poderia ser mudado, o que efetivamente aconteceu em alguns aspectos, como a obrigatoriedade do componente curricular Arte na LDBN 9394/96 e, posteriormente, a regulamentação da obrigatoriedade do estudo da arte local e regional, e das modalidades Artes Visuais, Dança, Música e Teatro (PIMENTEL 2017, p. 2840).
\end{abstract}

Com essa união de esforços, percebe-se a expansão e aumento de cursos de Licenciatura em Artes Visuais pelo país, no início do século XXI, o que vai somar em um numero expresivo de professores formados na modalidades de Artes Visuais.

Baseado nessas transformações emergentes, o Parecer CNE/CP №: 22/2019 justifica a necessidade de "revisão e atualização dos documentos que tem como objetivo atender a legislação vigente, a começar pela própria Lei no 9.394, de 20 de dezembro de 1996, de Diretrizes e Bases da Educação Nacional (LDB)" (Marques, Orengo et al 2021, p. 639), que prevê a adequação curricular dos cursos, programas ou ações para a formação inicial e continuada de professores. O estabelecido na Base Nacional Comum Curricular (BNCC), quando, no $\$ 8^{\circ}$ do seu art. 62 , incluído pela Lei no 13.415, de 16 de fevereiro de 2017, dispõe que os currículos dos cursos da formação de docentes terão por referência a BNCC.

E para isso foi necessario que as universidades revisasem seus documentos e buscassem alternativas para uma formação reflexiva, aliada as tecnologias educacionais, de forma a contribuir junto a formação profissional desses professores, com novas propostas metodológicas e refletindo sobre como associar as possibilidades trazidas pelas tecnologias digitais com a descoberta de novos caminhos para suas práticas profissionais.

\title{
A formação dos professores de artes visuais: novas possibilidades com as tecnologias digitais
}

Ao pensar o processo de formação inicial do professor de Artes Visuais na contemporaneidade, tem-se o diálogo do papel da arte no interior do currículo acadêmico determinado pelas instituições. Desse modo, partimos da ideia defendida por Ana Mae Barbosa ao enfatizar que "em Artes Visuais a relação entre objetivos e métodos é que vai apontar que saberes o professor deve dominar para ensinar" (BARBOSA 2016, p.15). Nesta relação influi o que o professor pensa ser o objetivo de ensinar Arte e o que a instituição determina como objetivo.

É nesse contexto de interação, que a Arte, como parte de todas as transformações sociais, não poderia estar distante das evoluções tecnológicas, criando novas possibilidades. Nesse sentido, Pimentel (2011, p.769) defende que "o ensino de Arte, 
nos dias de hoje, não pode se abster do uso de tecnologias contemporâneas, quer seja na produção artística, quer seja nos estudos sobre Arte". Para isso, é necessário refletir sobre esse componente na educação pela ótica da tecnologia, agilizando o desenvolvimento de novos conhecimentos, esperando que esse discente descubra novos caminhos para suas práticas profissionais.

Nesta perspectiva, é necessário formar o discente para essas novas formas de pensar arte, despertando uma consciência crítica e reflexiva dos seus fazeres. No entanto, faz-se necessário que as instituições de ensino superior reflitam sobre seus currículos para não cometer o equívoco de ofertar um curso que distancie a teoria da prática7. Pimenta (1997, p. 5), reforça sobre esta formação inicial para o professor

Em relação à formação inicial, pesquisas (Piconez, 1991; Pimenta, 1994; Leite, 1994) têm demonstrado que os cursos de formação, ao desenvolverem um currículo formal com conteúdos e atividades de estágios, distanciados da realidade das escolas, numa perspectiva burocrática e cartorial que não dá conta de captar as contradições presentes na prática social de educar, pouco têm contribuído para gestar uma nova identidade do profissional docente (PIMENTA 1997, p. 5).

É neste sentido, que os pesquisadores brasileiros vêm falando sobre uma unidade entre teoria e prática. Assim, faz-se necessário uma "imersão na linguagem artística" (COUTINHO, 2003 p.156), na qual deve haver essa unidade entre entre os saberes docentes, gerando uma prática pedagógica crítica, capaz de transformar e construir a formação do professor de Artes Visuais, tendo em vista os recursos que as novas tecnologias proporcionam para facilitar o processo de ensino e aprendizagem, uma vez que as TDICS promovem: rapidez no processamento de dados, possibilidade de acesso a bens culturais produzidos pela humanidade, o caráter interativo dessas novas ferramentas e possibilidade de compartilhamento instantâneo dos conhecimentos (CERNEV; GUERRA 2017, p.5).

No entanto, de nada adiantará a tecnologia estar presente nas universidades se os professores não estiverem dispostos a mudar sua prática, a fim de lidar com os diversos recursos e ferramentas tecnológicas. Sobre isto, Evangelista afirma que:

O principal papel do ensino de Arte e das novas tecnologias é formar um aluno com conhecimento, pois os cidadãos do século XXI precisam estar preparados para acompanhar o ritmo das transformações, o que implica saber

7 TEORIA E PRATICA- [...] os saberes teóricos propositivos se articulam, pois, aos saberes da prática, ao mesmo tempo ressignificando-os e sendo por eles ressignificados. O papel da teoria é oferecer aos professores perspectivas de análises para compreender os contextos históricos, sociais, culturais, organizacionais, e de si mesmos como profissionais, nos quais se dá sua atividade docente, para neles intervir, transformando-os. Daí é fundamental o permanente exercício da crítica das condições materiais nas quais o ensino ocorre (PIMENTA, 2005, p.26) 
identificar os melhores métodos de ensino e aprendizagem, saber aceitar e partilhar a informação e saber trabalhar em equipe: essas serão as chaves do sucesso na sociedade em rede (EVANGELISTA, 2011, p. 15).

Falar desse ritmo de transformações, significa dizer que os futuros docentes precisam ser preparados tambem para a precariedade do ensino das Artes nas escola, sejam elas as más condições materiais e espaciais, a falta de materiais e equipamentos adequados ou os baixos salários de professores, esses são alguns dos componentes da situação precária que exigirá do discente identificar os melhores métodos de ensino e aprendizagem.

Para tanto, é necessário pensar o ensino de Artes Visuais e das novas tecnologias dentro do processo de formação inicial do docente, de forma, que o acadêmico seja estimulado a vivenciar a prática tecnológica, possibilitando a criação e a interação com obras artísticas, criação e edição de imagens, dentre tantas outras possibilidades que se configuram em espaços para atividades e pesquisas que por sua vez, reverberarão em sua atuação na educação escolar e no desenvolvimento dos estudantes.

Nesse sentido, dispositivos legais como as Diretrizes Curriculares Nacionais que trata das diretrizes curriculares de formação de professores, revogada pela Resolução CNE/CP 2/2019 (BRASIL 2019), busca orientar as instituições de ensino superior, apontando diferentes caminhos e dimensões da iniciação à docência. Assim, entende-se que existem muitas implicações acerca da construção e identidade docente e que é necessário manter sempre essa união da teoria com a práxis em sala de aula.

Considerando a relevância que norteia a formação docente em Artes Visuais, infere-se que é possivel fazer uso de tecnologias simples na graduação (utilizar os recursos próximos, os que estão no celular, como uma câmera para ilustrar ou um programa gratuito para juntar as imagens e contar), tendo em vista as incertezas dos recursos tecnológicos na educação basica. Nesse sentido acredita-se que a análise comparativa curricular no curso de licenciatura em Artes Visuais da UFMA será capaz de auxiliar na compreensão das possíveis mudanças a caminho de uma formação que crie ambientes de aprendizagem que promovam a construção de conhecimento e permitam a integração das TDIC nas atividades curriculares.

\section{O curso de licenciatura em artes visuais da universidade federal do maranhão - análise do PCC}

Para fins dessa pesquisa, buscou-se analisar o PPC do curso de licenciatura em Artes Visuais da UFMA, objetivando analisar de forma comparativa os documentos de 2010 e 2017, a fim de observar possíveis mudanças relacionadas à inserção das tecnologias no currículo.

Dessa forma, convém destacar que o percurso histórico feito pelo curso de Artes no Brasil não é recente e passou por várias mudanças em sua trajetória. Exi- 
gindo que a formação em curso superior contemple a especificidade das linguagens artísticas e não mais a polivalência.

Nessa perspectiva da polivalência, a Arte está presente na UFMA desde 1970, inicialmente com o curso de Licenciatura em Desenho e Artes Plásticas, o qual em 1980, passou a se denominar Licenciatura em Educação Artística e com a reformulação deu origem a três novos cursos, sendo eles: Teatro (criado em 2004), Música (criado em 2007) e Artes Visuais, este constituído através do PPC 2010.

Foi dessa maneira, que os profissionais da área de Artes, construíram um referencial considerável sobre o ensino da arte e a formação de profissionais. Toda essa intensa mobilização, resultou num outro perfil para o ensino da arte na educação básica e, consequentemente, para os cursos superiores de arte (PPC 2010).

Enfim, problemas apontados pela Comissão Avaliadora do curso de Educação Artística, que a partir de 2009 foi gradualmente sendo extinto, tendo os últimos discentes, seu período de integralização terminando em 2016. Para equilibrar todas as demandas encontradas, foi necessário algumas reformulações que sanasse as lacunas encontradas, bem como a troca de nomenclatura para Licenciatura em Artes Visuais, constituindo o PPC de 2010, para atender às novas necessidades do contexto do ensino e das diversas modalidades de linguagens artísticas.

Considerando este aspecto, a reformulação aconteceu para responder todas às mudanças e exigências de um novo currículo que se adequasse a um novo modelo de formação como explicitado no PPC 2017:

\begin{abstract}
Visando uma formação estético-pedagógica consciente, que instigue nos sujeitos envolvidos a busca do aprimoramento constante, almeja-se um curso de graduação pautado na unidade e identidade da docência das Artes Visuais. [...] buscar-se-á, na concepção e desenvolvimento do currículo, promover um relacionamento complementar entre teoria e prática, que tenha como princípio, origem e finalidade, a articulação entre ensino, pesquisa e extensão (PPC 2017, p. 06).
\end{abstract}

No decorrer desse período, na UFMA teve início um processo de mobilização, tendo em vista, a necessidade de atualização. No que tange a revisão do PPC, em 2017 foram realizadas mudanças consideráveis, entrando em vigor um currículo mais equilibrado entre disciplinas práticas e teóricas, atendendo tanto interessados em se profissionalizar na docência como também na produção artística.

Atualmente, no referido documento, é possível perceber a oferta de algumas disciplinas com foco para o uso das tecnologias na educação. Para fins desta pesquisa, buscou-se observar a existência de disciplinas obrigatórias e optativas que tivessem relação com o uso das tecnologias na educação ou as mídias digitais, bem como, o modo que esse tema é tratado nos referidos documentos. Assim, foram também analisadas as ementas dessas disciplinas, procurando compreender como trazem a discussão sobre a formação inicial desse docente em Arte. 
Nas ementas analisadas, foram considerados os currículos de 2010 e 2017 , onde foi possível identificar que alguns componentes foram reformulados, desmembrando-se em dois novos componentes. Outras disciplinas tiveram suas nomenclaturas alteradas para atender às novas demandas na formação do professor de Artes Visuais como demonstra o quadro 1.

Quadro 1-Disciplinas afins com as Tecnologias educacionais

\begin{tabular}{|c|c|c|c|}
\hline $\begin{array}{l}\text { DISCIPLINAS } \\
2010 \\
\end{array}$ & $\begin{array}{c}\text { EMENTA } \\
2010 \\
\end{array}$ & $\begin{array}{c}\text { DISCIPLINAS } \\
2017 \\
\end{array}$ & $\begin{array}{c}\text { EMENTA } \\
2017 \\
\end{array}$ \\
\hline $\begin{array}{l}\text { FOTOGRAFIA E } \\
\text { CINEMA - 90h. }\end{array}$ & $\begin{array}{l}\text { História da fotografia. } \\
\text { Linguagem fotográfica. } \\
\text { Processos técnicos de } \\
\text { captação e processamento } \\
\text { da imagem fotográfica do } \\
\text { analógico ao digital. História } \\
\text { do cinema. Linguagem } \\
\text { cinematográfica. Estrutura } \\
\text { narrativa e gêneros } \\
\text { cinematográficos. Elementos } \\
\text { de análise fílmica. Escolas, } \\
\text { movimentos e tendências no } \\
\text { cinema mundial e brasileiro. } \\
\text { Cinema no Maranhão. }\end{array}$ & FOTOGRAFIA - 60h & $\begin{array}{l}\text { História da fotografia. } \\
\text { Elementos formais e } \\
\text { conceituais da linguagem } \\
\text { fotográfica. Processos } \\
\text { técnicos de captação, } \\
\text { processamento e } \\
\text { tratamento de imagem } \\
\text { fotográfica. Dispositivos } \\
\text { móveis. Prática fotográfica. }\end{array}$ \\
\hline $\begin{array}{l}\text { MÍDIAS } \\
\text { DIGITAIS } \\
\text { (AV) - 60h }\end{array}$ & $\begin{array}{l}\text { Transições tecnológicas, } \\
\text { do analógico ao digital; } \\
\text { As TICs e os modos de } \\
\text { interagir, criar e comunicar. } \\
\text { Apropriação e utilização das } \\
\text { TICs no desenvolvimento } \\
\text { de produtos culturais no } \\
\text { ambiente digital. }\end{array}$ & $\begin{array}{l}\text { LABORATÓRIO DE } \\
\text { PRODUÇÃO EM } \\
\text { AUDIOVISUAL } 60 \mathrm{~h} .\end{array}$ & $\begin{array}{l}\text { Audiovisual e novas mídias. } \\
\text { Elementos constitutivos } \\
\text { da linguagem audiovisual. } \\
\text { Argumento, sinopse } \\
\text { e Longlines. Conceito } \\
\text { e função do roteiro. } \\
\text { Estrutura narrativa. } \\
\text { Desenvolvimentos de } \\
\text { projetos em audiovisual. } \\
\text { Pré-produção, produção e } \\
\text { pós-produção. }\end{array}$ \\
\hline
\end{tabular}




\begin{tabular}{|c|c|c|c|}
\hline $\begin{array}{c}\text { DISCIPLINAS } \\
2010 \\
\end{array}$ & $\begin{array}{c}\text { EMENTA } \\
2010 \\
\end{array}$ & $\begin{array}{c}\text { DISCIPLINAS } \\
2017 \\
\end{array}$ & $\begin{array}{c}\text { EMENTA } \\
2017 \\
\end{array}$ \\
\hline $\begin{array}{l}\text { EDUCAÇÃO E } \\
\text { MULTIMEIOS } \\
\text { (AV) - 60h }\end{array}$ & $\begin{array}{l}\text { Midiatização da sociedade. } \\
\text { Experiência pedagógica, } \\
\text { inteligência coletiva e } \\
\text { midiatização do ensino. } \\
\text { Educação intercultural } \\
\text { como prática de } \\
\text { intervenção. Estratégias e } \\
\text { tecnologias de produção } \\
\text { colaborativas, participativas } \\
\text { e compartilhadas de } \\
\text { conhecimentos. Concepção } \\
\text { e utilização de sítios } \\
\text { eletrônicos, web designer. } \\
\text { Trabalho cooperativo on-line: } \\
\text { o usuário como fornecedor } \\
\text { de informações. Estudo } \\
\text { do processo de ensino/ } \\
\text { aprendizagem a partir de } \\
\text { recursos da Internet e outras } \\
\text { mídias eletrônicas. }\end{array}$ & $\begin{array}{l} \\
\\
\text { TECNOLOGIAS DA } \\
\text { INFORMAÇÃO E DA } \\
\text { COMUNICAÇÃO } \\
\text { NO ENSINO DE } \\
\text { ARTES VISUAIS - } \\
\text { 6Oh }\end{array}$ & $\begin{array}{l}\text { Investigação dos recursos } \\
\text { produzidos pelas (TICs) } \\
\text { como instrumento, auxílio } \\
\text { e fonte complementares à } \\
\text { pesquisa e ao aprendizado. } \\
\text { Análise das práticas } \\
\text { metodologias educacionais } \\
\text { para fins pedagógicos } \\
\text { na alfabetização em } \\
\text { tecnologia e na inclusão } \\
\text { digital. Análise crítica das } \\
\text { estratégias desenvolvidas e } \\
\text { aplicadas na divulgação da } \\
\text { informação contidas } \\
\text { na rede. }\end{array}$ \\
\hline
\end{tabular}

Fonte: Autor da pesquisa com base nas informações do PPC 2010 e 2017

A partir do quadro 1, é possível perceber que o componente curricular Fotografia e Cinema foi desmembrado, gerando duas disciplinas independentes que somam juntas uma carga horária superior à anterior, tendo em vista, que teria que atender as novas revisões feitas na ementa, como o acréscimo do conteúdo - dispositivos móveis.

Já a disciplina Mídias Digitais, também sofreu alterações, tendo sua nomenclatura alterada para Laboratório de produção em audiovisual, no intuito de atender às novas exigências de aliar teoria e prática. Ela traz em sua ementa ,a relação entre arte e tecnologia através do conteúdo descrito no quadro 1.

Outra mudança bem significativa evidenciada no quadro 1, foi a mudança de nomenclatura da disciplina de Educação e Multimeios, para Tecnologias de informação e comunicação (TICs) no ensino das Artes Visuais, que traz em sua ementa um caráter bem mais abrangente e necessário para a formação do discente, com conteúdos que atendem as metodologias educacionais indispensáveis ao dia a dia do professor em sala de aula.

O que se percebe através da comparação entre as ementas, é que a mudança de paradigmas e a velocidade com que as tecnologias adentraram a Universidade, 
exigiu alterações em seus documentos de forma a reverberar em suas práticas, e na sua futura vivência educacional.

Essas mudanças exigiram que a academia formasse licenciados com um novo perfil, que além de dominar os elementos constitutivos da linguagem visual, consigam trabalhá-los a partir das novas mídias, estabelecendo conexões com outras linguagens artísticas e com as demais áreas do conhecimento (PPC 2017).

No intuito de inserir os licenciandos nesse contexto de educação contemporânea, a disciplina Arte e as novas Tecnologias traz informações básicas como fica evidente no quadro 2.

Quadro 2-Componentes da Investigação Prática Afins as Tecnologias

\begin{tabular}{|l|l|}
\hline \multicolumn{1}{|c|}{ DISCIPLINAS 2017 } & \multicolumn{1}{c|}{ EMENTA } \\
\hline ARTE E NOVAS TECNOLOGIAS - 60h & $\begin{array}{l}\text { Conceito de tecnologia. Relações entre } \\
\text { Arte e novas tecnologias. As TICs e mídias } \\
\text { contemporâneas na Arte. Museus virtuais como } \\
\text { laboratório de pesquisa em artes. Produção } \\
\text { artística no ciberespaço. Redes sociais no } \\
\text { ciberespaço: possibilidades de aplicação no } \\
\text { ensino da arte. Concepções contemporâneas do } \\
\text { ensino da arte incorporando as novas tecnologias. }\end{array}$ \\
\hline
\end{tabular}

Fonte: Autor da pesquisa com base nas informações do PPC 2017

Observa-se nesse quadro, que o Componente da investigação prática afins as tecnologias, presente no PPC de 2017, teve o acréscimo da disciplina Arte e as novas Tecnologias, ofertada no quinto período do curso de Artes Visuais com uma carga horária de 60 horas. Visando atender as mudanças ocasionadas pelas revoluções tecnológicas no ensino de Arte, e com intuito de oferecer perspectivas didáticas através do uso de tecnologias no ensino, percebe-se o surgimento de novas formas de interação com obras de arte através de varias ferramentas que possibilitam criar e editar imagens, conhecer e redigir roteiros de peças teatrais, escutar música, assistir filmes e espetáculos, acessar virtualmente museus, galerias de arte e sites de artistas em ângulo de $360^{\circ}$ e interagir com as obras nesses ambientes virtuais.

De acordo com os documentos analisados, para contribuir com a formação do discente, a forma de disponibilizar outras disciplinas como as optativas/obrigatórias foi alterada, desobrigando o curso de Artes Visuais de ofertá-las, considerando os problemas enfrentados pelos discentes com a matriz curricular de 2010, que por não serem disponibilizadas no prazo regular, muitas vezes por falta de professores disponíveis do curso, deixavam uma lacuna na formação dos mesmos. 
No intuito de resolver a situação, foram elencadas disciplinas regulares de outros cursos da UFMA, que contribuem na formação do discente de Artes Visuais, em consonância à proposta do Projeto Pedagógico Institucional - PPI da UFMA, que incentiva a interdisciplinaridade. Dessa forma, ele deverá em qualquer momento do curso realizar 03 (três) disciplinas optativas, somando a carga horária de no mínimo $180 \mathrm{~h}$ dos cursos de graduação da UFMA campus São Luís. A escolha deve ser feita nos cursos: Música, Teatro, Design, Pedagogia, Comunicação Social e Estudos Africanos e Afro-Brasileiros, dentre as quais também encontramos algumas disciplinas com afinidade ao campo tecnológico, sendo elas: Cor e Imagem Digital no curso de Design e Fundamentos da Linguagem Audiovisual no curso de comunicação social, como é possível observar no quadro 3.

Quadro 3-Disciplinas Optativas- Componentes da Investigação Prática Afins as Tecnologias

\begin{tabular}{|l|l|l|}
\hline DISCIPLINA & \multicolumn{1}{|c|}{ CURSO } & \multicolumn{1}{c|}{ EMENTA } \\
\hline COR E IMAGEM DIGITAL- 60h & Design & $\begin{array}{l}\text { A imagem digital: conceitos e teorias. } \\
\text { Tipos de imagens. Estética Visual, } \\
\text { fotografia e as alterações provocadas } \\
\text { pela fotografia digital. A manipulação } \\
\text { da imagem digital: conceitos, teorias } \\
\text { e questões éticas. Sistemas de cor em } \\
\text { espaços digitais. Recursos para entrada } \\
\text { e saída de informações: equipamentos e } \\
\text { técnicas. Produção de fotografia digital: } \\
\text { equipamentos, programas de manipulação } \\
\text { e tratamento e sistemas de suporte. } \\
\text { Armazenamento de imagem digital. }\end{array}$ \\
\hline PROJETO GRÁFICO I - 60h & Design & $\begin{array}{l}\text { Idealização de soluções para problemas } \\
\text { de design gráfico de baixa complexidade } \\
\text { e natureza impressa. Estuda aspectos } \\
\text { metodológicos e evoluções tecnológicas } \\
\text { da mídia impressa. Aborda as questões } \\
\text { conceituais da construção de signos para } \\
\text { a elaboração de uma sintaxe visual. }\end{array}$ \\
& & \\
\hline
\end{tabular}




\begin{tabular}{|c|c|c|}
\hline DISCIPLINA & CURSO & EMENTA \\
\hline $\begin{array}{l}\text { DIREÇÃO DE ARTE E } \\
\text { CENOGRAFIA -60h }\end{array}$ & Comunicação social & $\begin{array}{l}\text { Concepção visual e efeitos estéticos } \\
\text { dos elementos de composição em } \\
\text { produções audiovisuais. Luz, sombra e } \\
\text { cor. lluminação sob a ótica do diretor } \\
\text { de arte. Percepção do espaço. Pesquisa } \\
\text { de material e equipe de trabalho. } \\
\text { Indumentária, maquiagem e objetos de } \\
\text { cena. Caracterização de personagem } \\
\text { em dramaturgia. Cenários reais, virtuais, } \\
\text { locações externas e ambientação em } \\
\text { geral. Identidade visual, assinaturas, } \\
\text { vinhetas e efeitos visuais. }\end{array}$ \\
\hline $\begin{array}{l}\text { INFORMÁTICA APLICADA À } \\
\text { EDUCAÇÃO - 75h }\end{array}$ & Pedagogia & $\begin{array}{l}\text { As novas TICs e suas contribuições no } \\
\text { campo educacional. Os recursos da } \\
\text { informática e sua utilização no contexto } \\
\text { ensino-aprendizagem. } \\
\text { Noções básicas de informática: a } \\
\text { utilização do editor de textos Word, do } \\
\text { PowerPoint na elaboração de recursos } \\
\text { didáticos, da Internet e do correio } \\
\text { eletrônico. Ferramentas de busca e seu } \\
\text { uso na pesquisa. Softwares educativos e } \\
\text { sua exploração em sala de aula }\end{array}$ \\
\hline
\end{tabular}

Fonte: Autor da pesquisa com base nas informações do PPC 2017

Nos disciplinas apresentadas no quadro 3, percebe-se através da análise das ementas que as disciplinas ofertadas como optativas, são de extrema relevância para a formação em Artes Visuais, no entanto, a lacuna percebida é que caso o discente não opte por esse componente curricular sairá com uma falha em sua formação acadêmica, considerando que o conteúdo observado na ementa, não está presente em outras disciplinas regulares e atenderia a uma variedade de público.

Por meio dos dados apresentados, foi possível identificar através da comparação das ementas que disciplinas como Fotografia, Cinema e vídeo, Tecnologias de informação e comunicação, Arte e as novas Tecnologias já relacionam à utilização das tecnologias as Artes Visuais, sendo essa uma experiência fundamental para o(a) licenciando(a) relacionar a teoria com prática e refletir sobre o fortalecimento do vínculo entre universidade e educação básica.

Para tanto, a análise comparativa realizada entre os PPC's do curso de Artes Visuais da UFMA para essa pesquisa, levou-nos a identificar mudanças na formação 
inicial dos discentes, principalmente relacionadas à inserção das tecnologias no currículo do curso, bem como, em sua matriz curricular e em suas ementas, o que nos leva a crer que a UFMA e seus docentes estão concentrando seus esforços na atualização desses projetos pedagógicos, no intuito de responder a aplicação de novas didáticas, metodologias e estratégias na identidade do profissional licenciado em Artes Visuais da sociedade contemporânea.

\section{Considerações finais}

Torna-se relevante refletir sobre a inserção das TDICS no currículo das universidades e na formação inicial de professores de Artes Visuais, para que estas sejam capazes de integrá-las ao processo de ensino e aprendizagem. Deste modo, é imprescindível que o espaço acadêmico, forme profissionais da educação aptos a utilizarem as mídias digitais em todo o seu potencial de flexibilidade, apropriação e produção de conhecimento com fins pedagógicos.

É notório que as tecnologias digitais chegaram à Universidade, e o desafio posto por elas é gigantesco. Na licenciatura em Artes Visuais, não é diferente, tendo em vista que precisa-se formar os discentes no âmbito teórico e prático para conhecer e interagir com as particularidades dessa nova cultura, que tem adentrado de forma tão rápida os espaços acadêmicos e que muitas vezes ficam em desuso na educação básica, seja por falta de informação suficiente, ou habilidade para o uso eficaz dos recursos tecnológicos disponíveis no contexto educativo.

O propósito deste trabalho foi refletir sobre as conjecturas acerca do impacto da tecnologia na formação inicial dos professores de Artes Visuais na UFMA, e sua relação com os recursos disponíveis, observados a partir da comparação entre os PPC's de 2010 e 2017, e suas disciplinas e ementas. Pode-se identificar que a forma de pensar a prática docente dos discentes tem sido modificada através de disciplinas, como laboratório de produção em audiovisual, dentre outras, ofertadas numa perspectiva de práxis pedagógica.

Para tanto, através de nossa análise nos documentos mencionados, foi possível compreender que disciplinas como: laboratório de produção em audiovisual, tecnologias da informação e da comunicação no ensino de artes visuais, arte e novas tecnologias, dentre outras citadas ao longo do trabalho, visam atender a reestruturação do curso de Artes Visuais, mas também suprir a demanda de um público que é interativo e conectado.

No entanto, infere-se que somente a presença do tema abordado no projeto pedagógico da Licenciatura em Artes Visuais da UFMA, e nas disciplinas acima citadas, não são suficientes para assegurar a esse discente o domínio de tais conhecimentos, a ponto de transformá-los em prática pedagógica.

Um dos pontos discordantes encontrados na análise foi quanto às disciplinas ofertadas como optativas, pois de acordo com a ementa, considera-se de extrema relevância a matrícula dos acadêmicos de Arte nessas disciplinas, pois, caso o dis- 
cente não opte por matricular-se nos componentes Cor e Imagem Digital e Fundamentos da Linguagem Audiovisual, sairão com lacunas, uma vez que elas agregam outros conhecimentos acerca da temática.

Quanto à formação desse futuro professor de Artes Visuais, foi possível perceber que há um movimento para a construção de um novo perfil de profissional, porém, exige do discente autonomia e protagonismo, para atender a concretização de novas exigências no campo da formação em Arte. Dessa forma, é necessário um empenho pessoal expressivo para adquirir habilidades técnicas e domínio pedagógico acerca das novas tecnologias, uma vez que elas são capazes de ajudar no aprendizado a partir do momento em que o professor se apropria desse conhecimento.

Assim, pode-se reiterar que as tecnologias digitais na contemporaneidade, colocam-se a favor da educação, podendo ser aliada do professor e do espaço acadêmico, desde que, não seja utilizada no seu formato tradicional apenas como lousa, ou como mais um instrumento pelo qual o professor transmite conteúdos e o discente absorve passivamente, sem proporcionar a este a condição do mesmo trabalhar e interagir através de um veículo onde ele tenha interesse para transformá-lo em estratégia de construção de conhecimento crítico dos sujeitos, em uma relação dinâmica, ativa e dialógica.

Nessa perspectiva, é necessário uma reconfiguração constante, para atender a ampliação e criação de novas práticas pedagógicas que potencializam a interação entre os envolvidos nos processos de ensino e aprendizagem, tendo em vista que a variedade de recursos tecnológicos existentes melhoram a qualidade e o desenvolvimento das aulas de arte, a fim de torná-las mais atrativas, no entanto, sozinhas não há garantia de que são capazes de mediar a aprendizagem.

Pretende-se aprofundar esse estudo sobre a formação docente do acadêmico em Artes Visuais, por entender que é necessário escutá-los, bem como seus professores, para entender como ambos se sentem em relação às tecnologias digitais, mensurando se o que está presente no PPC do curso de Artes Visuais da UFMA, de fato consegue atender ao que está preconizado no documento ou se os discentes ainda sentem lacunas em sua formação para trabalhar com esses recursos na produção de conhecimentos em Arte. 


\section{Referências}

BARBOSA, Ana Mae. ARTE /EDUCAÇÃO: formando professores. In: PIMENTEL, Lucia Gouvêa. A prática artística docente como metodologia para a formação de professores. Revista CLEA, v. 1, p. 50-57 maio/jun. 2016.

BRASIL. MEC. CNE. Conselho Pleno. Parecer CNE/CES n 22, de 07 de novembro de 2019. Diário Oficial da União, Brasília, 2019. Disponível em: http://portal.mec.gov. br/ index.php?option=com_docman\&view =download\&alias=133091-pcp022-193\&category slug=dezembro-2019-pdf\&ltemid=30192. Acesso em: 29 março 2020.

CERNEV, Francine K.; GUERRA, Renata R. TecnoArte: uso das tecnologias digitais num curso de formação continuada com professores de Artes. XXIII Congresso Nacional da Associação Brasileira de Educação Musical. Manaus, 16 a 20 de outubro de 2017. Disponível em: http://abemeducacaomusical.com.br/conferencias/index. php/congresso2017/cn a/paper/viewFile/2597/1390. Acesso em 26 Nov. 2020.

COUTINHO, Rejane G. A Formação de Professores de Arte. In: BARBOSA, Ana Mae. (org). Inquietações e Mudanças no Ensino da Arte. 2ª Ed. São Paulo, Cortez: 2003.

EVANGELISTA, Caroline da Silva. O Ensino da Arte através do Computador: Uma Proposta de Prática Pedagógica para o Ensino Fundamental. V Colóquio Internacional: "Educação e Contemporaneidade", São Cristovão- SE/Brasil, p. 1-16, Setembro de 2011.

FRIZON, Vanessa; et.al. A formação de professores e as tecnologias digitais. Anais do XII Congresso Nacional de Educação - EDUCERE, 2015. Disponível em: https: https:// educere.bruc.com.br/arquivo/pdf2015/22806_11114.pdf. Acesso em 02 Out. 2020.

LIMA, L.; LOUREIRO, R. C. Tecnodocência: concepções teóricas. Fortaleza: Edições UFC, 2019.

MARQUES, Elson Luiz Reyes; ORENGO, Gilberto; MÜLLER, Maykon Gonçalves; BUSS, Cristiano da Silva; SILVA, Marcos André Betemps Vaz da. Novas Diretrizes Curriculares Nacionais para a Formação Inicial de Professores para a Educação Básica: avanços ou retrocessos. Revista Educar Mais. 2021 | Volume 5 | № 3 | Pág. 637 a 649.

MORAN, J. Tablets e ultrabooks na educação. IN: MORAN, J. Novas Tecnologias e Mediação Pedagógica. 21a ed. Campinas, SP: Papirus, 2013. 
PPC. Projeto Pedagógico do Curso de Licenciatura em Artes Visuais 2010.

Ministério da Educação. Universidade Federal do Maranhão - UFMA. NDE, 2010.

Disponível em: https://sigaa.ufma.br/sigaa/

verProducao? idProducao=320361\&key=048aa35aa0354adbb1a394467b6f578c.

Acesso em: 20 Fev. 2021.

Projeto Pedagógico do Curso de Licenciatura em Artes Visuais 2017.

Ministério da Educação. Universidade Federal do Maranhão - UFMA. NDE, 2017.

Disponível em:https://sigaa.ufma.br/sigaa/

verProducao? idProducao=320361\&key=048aa35aa0354adbb1a394467b6f578c.

Acesso em: 20 Fev. 2021.

PIMENTA S. G. Formação de professores: saberes e a identidade da docência.

Revista Nuances Vol. III- setembro de 1997. Disponível em: https://revista.fct. unesp.br/index.php/Nuances/article/view/50/0. Acesso em: 20 Fev. 2021.

PIMENTEL, Lucia Gouvêa. Novas territorialidades e identidades culturais: 0 ensino de arte e as tecnologias contemporâneas. Anais da ANPAP, pp.765-771, 2011. Disponível em: http://www.anpap.org.br/anais/2011/pdf/ceav/lucia_gouvea_ pimentel.pdf. Acesso em: 03 Jan. 2021.

PIMENTEL, Lucia Gouvêa. ONTENS E HOJES NÃO FAZEM UM AMANHÃ:

aprendizagens resistentes em artes visuais.26 encontro da associação nacional de pesquisadores em Artes Plasticas Memória e inventaÇÕES. Campinas, 25 a 29 de setembro de 2017.

Submetido em 18/08/2021

Aprovado em 22/10/2021 